\title{
MERANCANG APLIKASI SMS GATEWAY SEBAGAI UPAYA PELAYANAN INFORMASI KEPATUHAN WAJIB PAJAK DI KPP PRATAMA PALU
}

\author{
J. Khairiah¹, R. Ratianingsih², D. Lusiyanti ${ }^{3}$ \\ 1,2,3Program Studi Matematika Jurusan Matematika FMIPA Universitas Tadulako \\ Jalan Soekarno-Hatta Km. 09 Tondo, Palu 94118, Indonesia. \\ 1jamiatul.khairiah11@yahoo.co.id, 2ratianingsih@yahoo.com, 3Desylusiyanti@yahoo.com
}

\begin{abstract}
In order to optimize the tax revenue, many program, have been launched for tax payers in order to get the quickly tax revenue realization. According to the tax payer of KPP Pratama Palu, to improve the awareness, the institution reports and remittances the SPT period regularly such that no occurrence is occured. In the globalization era, many creativities and sophisticated communication tools inspiring this research to design sms gateway application. The idea is also motivated by the phenomena of many mobile phones tipes that have definitely SMS feature which support 3G, touch screen, dual SIM, etc. SMS Gateway is designed as a tools to send any information and to remind the tax payer. By using the application, hopefully the arrears could be minimized and the tax revenue could be optimized. The application is designed based on PHP (as the programming language), MYSQL (as the databse) and Apache (as the webserver). SMS also be sent even the phone is turned off. The resulted application shows that the taxpayer compliance information services is well done and cheap enough to be implemented.
\end{abstract}

Keywords : Gammu, KPP Pratama Palu, SMS Gateway

\section{ABSTRAK}

Upaya untuk lebih mengoptimalkan penerimaan pajak telah banyak dilakukan melalui berbagai program kepada wajib pajak, sehingga penerimaan pajak dapat terealisasikan dengan cepat. Surat menyurat kepada wajib pajak yang telah dilakukan pihak KPP Pratama Palu merupakan salah satu program pengoptimalan penerimaan pajak. Hal ini masih sangat kurang menyadarkan wajib pajak bagi masyarakat agar kiranya dapat melakukan pelaporan dan penyetoran SPT Masa secara rutin sehingga tidak terjadinya penunggakan. Untuk itu diera globalisasi saat ini berbagai kreatifitas serta kecanggihan alat komunikasi menjadikan penelitian ini merancang aplikasi sms gateway terlebih lagi semua tipe handphone pasti memiliki fitur SMS, baik yang mendukung 3G, touch screen, dual SIM, dll. SMS pun juga dapat dikirim walau handphone dalam keadaan mati. Sms gateway bisa dijadikan sebagai wadah pengiriman informasi sebagai pengingat wajib pajak sehingga penunggakan dapat terminimalisir dan penerimaan pajak optimal. Aplikasi ini dirancang sedemikian rupa yakni, PHP sebagai bahasa pemogramannya, MySQL sebagai databasenya serta Apache sebagai webservernya, sehingga menghasilkan layanan informasi kepatuhan wajib pajak dengan tarif yang murah yaitu 3000 rupiah untuk setiap pengiriman informasi kepada wajib pajak sekaligus ke berbagai operator.

Kata Kunci : Gammu, KPP Pratama Palu, SMS Gateway 


\section{PENDAHULUAN}

Negara Indonesia saat ini terus melaksanakan pembangunan nasional secara berkesinambungan dan berkelanjutan. Di sisi lain terjadinya krisis yang dialami dunia saat ini sangat mempengaruhi kestabilan ekonomi nasional dalam melaksanakan pembangunan nasional. Bangsa ini tentu membutuhkan dana yang sangat besar untuk melaksanakan hal tersebut. Adapun sumber dana pembangunan nasional selama ini berupa penerimaan negara yang berasal dari dalam maupun luar negeri. Agar pembangunan nasional dapat tetap berjalan dengan baik dan berkesinambungan diperlukan dana yang tidak sedikit. Salah satu sumber penerimaan negara adalah pajak (Sandri Prabowo, 2010). Pajak merupakan penerimaan negara yang utama dan mempunyai potensi yang sangat besar. Usaha-usaha untuk lebih meningkatkan penerimaan pajak ini telah banyak dilakukan melalui berbagai program seperti dengan membuat beberapa kebijakan, antara lain: menyempurnakan sistem administrasi perpajakan, menyempurnakan peraturan perpajakan, melanjutkan program ekstensifikasi wajib pajak, meningkatkan intensifikasi pemungutan pajak, dan meningkatkan pelayanan kepada wajib pajak.

Dalam meningkatkan penerimaan pajak, Direktorat Jenderal Pajak (DJP) sangat tergantung pada unit kerja yang ada di bawahnya, dalam hal ini Kantor Pelayanan Pajak Pratama (KPP Pratama) dan Kantor Pelayanan, Penyuluhan, dan Konsultasi Perpajakan (KP2KP) yang merupakan Satuan Kerja (Satker) dari Kantor wilayah Direktorat Jenderal Pajak (Kanwil DJP). Satker-satker memiliki tanggung jawab untuk membuka kesadaran masyarakat akan kewajiban membayar pajak sehingga penerimaan pajak akan sesuai target. Pada saat melakukan magang angkatan XIX di KPP Pratama Palu ditemukan fenomena penunggakan oleh wajib pajak. Penelitian ini menawarkan upaya penanganan masalah tersebut mengingatkan wajib pajak untuk membayar pajak melalui sistem pengingat dalam bentuk sms gateway. Aplikasi tersebut diharapkan dapat memberikan informasi secara cepat dan tepat untuk wajib pajak di KPP Pratama Palu, dengan pelayanan yang murah dan tepat.

\section{METODE PENELITIAN}

1. Memulai Penelitian.

2. Mengumpulkan Data

3. Membuat desain rancangan aplikasi

4. Membuat perancangan sms gateway

5. Menjalankan dan Implementasi Aplikasi

6. Menyimpulkan hasil penelitian.

7. Selesai. 


\section{HASIL DAN PEMBAHASAN}

\subsection{Membuat Desain Rancangan Aplikasi}

Aplikasi yang akan dirancang merupakan aplikasi layanan pengiriman informasi. Aplikasii yang akan dibuat ini bersifat internal yakni, pengguna program ini hanya pihak tertentu saja yang memiliki hak akses terhadap program ini. Rancangan tersebut meliputi desain login, desain struktur menu, dan desain input.

1) Desain Login

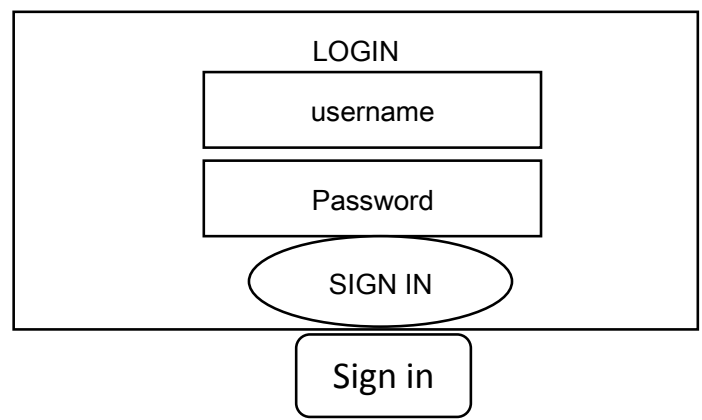

Gambar 1 : Desain login

Desain login merupakan desain yang umum digunakan untuk keamanan aplikasi. Desain login berisikan username dan password, penelitian kali ini pengisian username dan password dapat menggunakan huruf, angka maupun kombinasinya.

\section{2) Desain struktur menu}

merupakan struktur yang digunakan untuk membantu peneliti dalam merancang aplikasi yang sesuai dengan kebutuhan peneliti. Menu dirancang untuk dapat mengidentifikasi kepatuhan pajak dalam mendaftarkan diri, menyetorkan kembali SPT, perhitungan dan pembayaran pajak terutang dan pembayaran tunggakan. Dalam penelitian ini aplikasi hanya member ruang kepada wajib pajak mendaftarkan diri sebagai upaya pelayanan informasi dalam penyetoran SPT masa dan pembayaran pajak. Berikut akan dijelaskan secara singkat pembagian struktur menu pada aplikasi ini: 


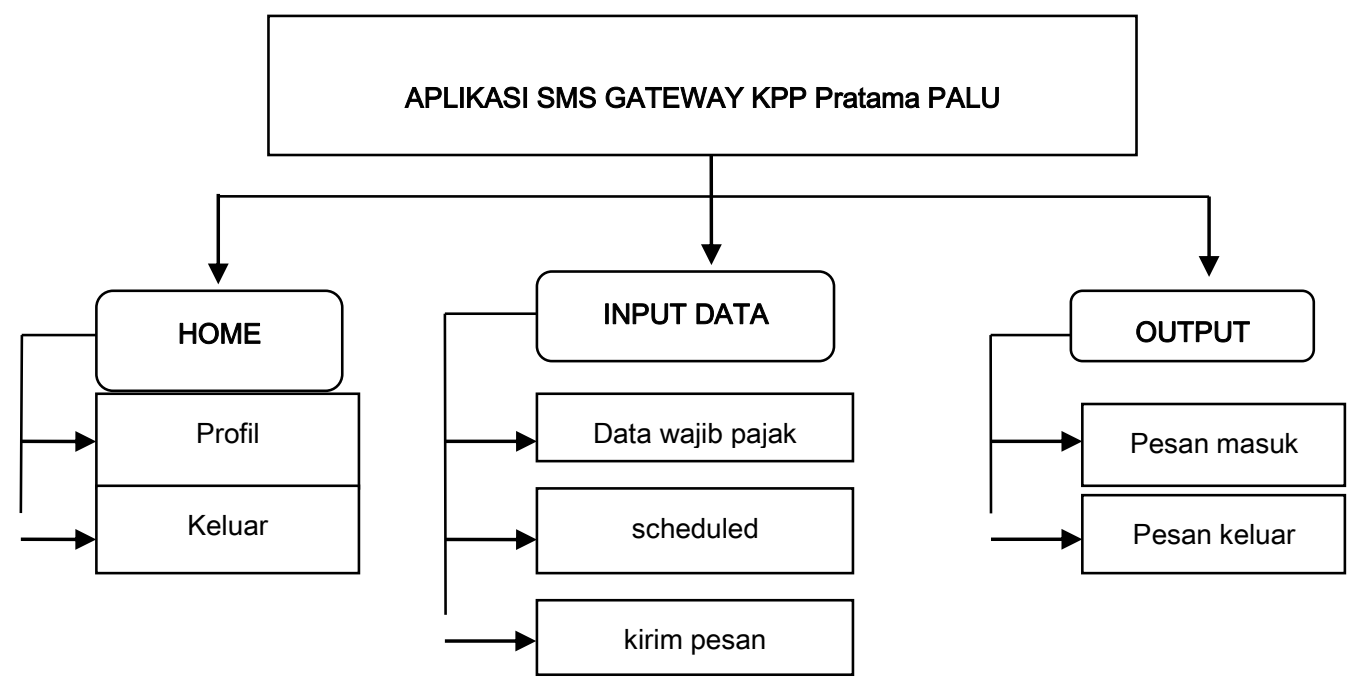

Gambar 2 : Desain Menu utama

Struktur menu bertujuan untuk memudahkan penulis dalam merancang aplikasi sms gateway. Komponen yang ada didalamnya tersusun sedemikian rupa hingga menjadikan admin mudah saat menggunakan. Untuk lebih jelasnya peneliti membuat diagram entity untuk memperlihatkan komponen secara detail pada menu utama sebagai berikut:

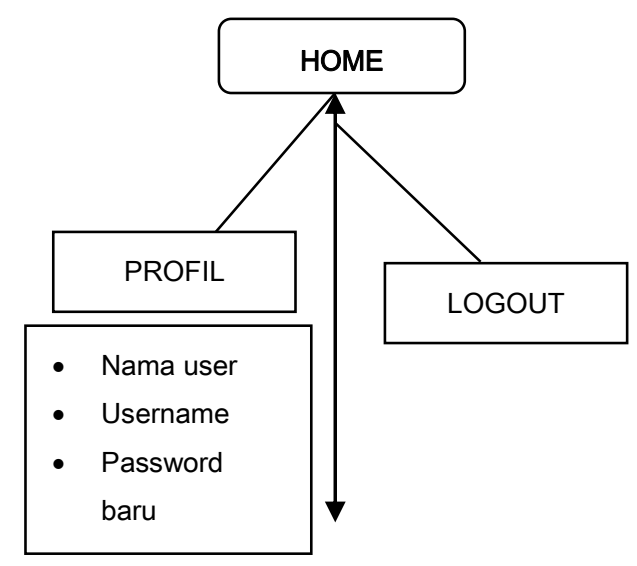



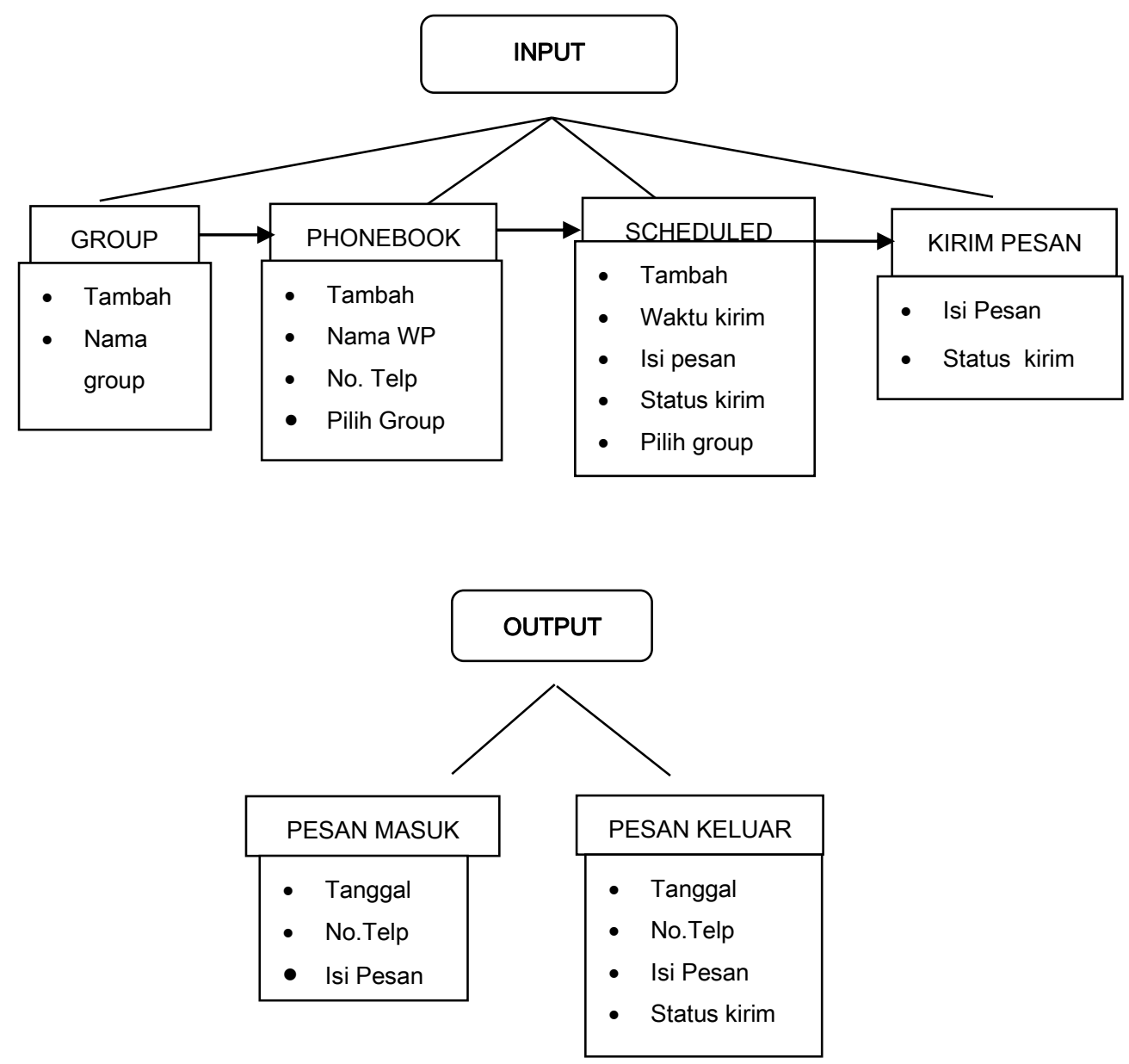

Gambar 3 : diagram entity menu utama

Gambar 2 menggambarkan desain struktur menu secara detail dimana ada tiga kategori yaitu home, input dan output. Home, yang berisikan profil, berisikan nama user yang berfungsi untuk merubah nama home sesuai yang ditetapkan, username berfungsi sebagai ID admin, password baru yang berfungsi untuk merubah password yang lama. Sedangkan home yang berisikan logout berfungsi untuk keluar dari aplikasi. Input berisikan group, phonebook, schedule dan kirim pesan yang berisikan fasilitas tambah yang berfungsi berturut-turut menambahkan nama group, menambahkan nama wajib pajak, no.telp serta pilih group. Fasilitas Schedule berfungsi sebagai penjadwalan pengiriman pesan kesemua group atau ke semua jenis pajak "badan" dan kesemua jenis pajak "orang pribadi". Schedule juga berisikan status kirim "belum kirim" dan "sudah kirim". Fasilitas kirim pesan berfungsi sebagai tempat pengiriman kembali pesan yang memiliki status kirim "error" "sehingga 
pengiriman dilakukan pada satu nomor. Output berisikan kotak masuk dan kotak keluar dimana kotak masuk berisikan pesan yang masuk yang didalamnya terdapat tanggal penerimaan pesan, isi pesan serta no.telp. Kotak keluar yang berfungsi sebagai tempat melihat pengiriman pesan memiliki status kirim yang berfungsi sebagai pemberitahuan pada admin pesan yang berstatus "error" dan "terkirim. Jika pesan berstatus eror maka admin mengirim pesan kembali pada kirim pesan.

3) Desain input

Input merupakan awal mulanya suatu proses informasi. Penginputan yang dilakukan yaitu pengiputan nama group dan data wajib pajak yang berupa nama dan nomor handphone serta jenis pajak yang dimasukkan kedalam group.

\subsection{Membuat Perancangan Sms Gateway}

Untuk membuat SMS Gateway, perlu dipersiapkan Gammu for Windows, HP atau Modem GSM+Kabel Data, Driver HP/Modem, Apache dan MySQL. Perancangan dimulai dengan alur sebagai berikut:

1. Mengekstrak Gammu ke drive $C$ komputer.

2. Menginstal Xampp sehingga terinstall pula Apache+MySQL.

3. Mengkoneksikan Gammu, Xampp dan Modem. Meliputi Konfigurasi Gammurc, Konfigurasi smsdrc dan install jalankan server Gammu.

\subsection{Menjalankan Program Sms Gateway}

Membuka google chrome dan menuliskan halaman pencarian dengan alamat localhost/sms pajak dan dengan menekan tombol enter maka akan muncul username serta password selajutnya admin mengisinya. Setelah masuk kedalam aplikasi, admin wajib menjalankan server yang terdapat pada tampilan yang paling bawah. Sehingga memungkinkan pengiriman sms dapat berjalan.

\subsection{Implementasi}

Aplikasi layanan informasi melalui sms gateway diperlukan suatu database yang diberi nama smspajak. Database yang diperlukan dalam penyelesaian sistem layanan informasi meliputi input group dan phonebook. Penginputan group dilakukan, dikarenakan terdapat pemilihan group pada penginputan phonebook.

a) Pengiriman nomor handphone yang terdaftar.

Pengiriman nomor handphone yang terdaftar memudahkan admin dalam memberikan pelayanan informasi kepada semua wajib pajak. 


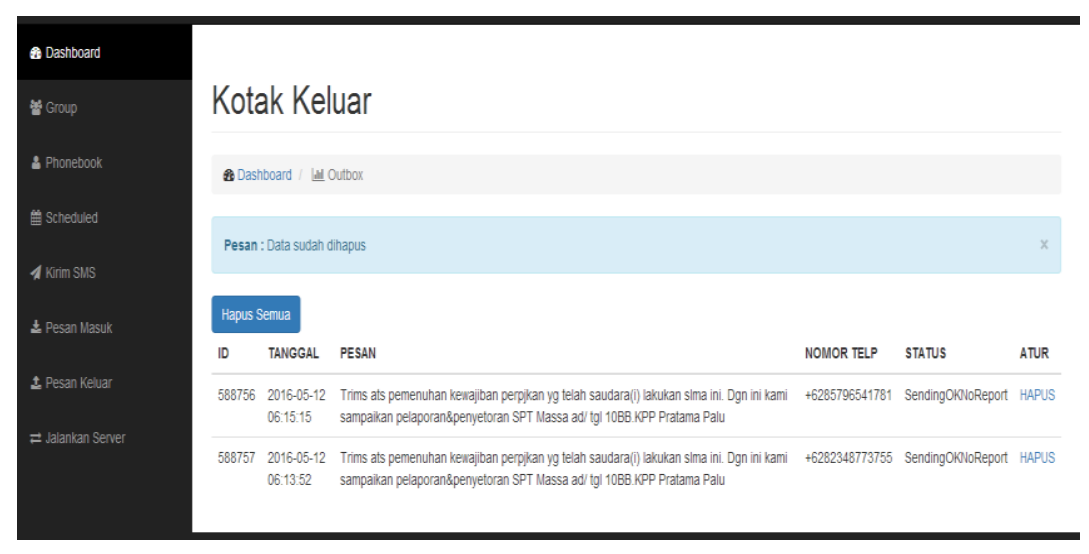

Gambar 4 : Kotak keluar (Status pengiriman)

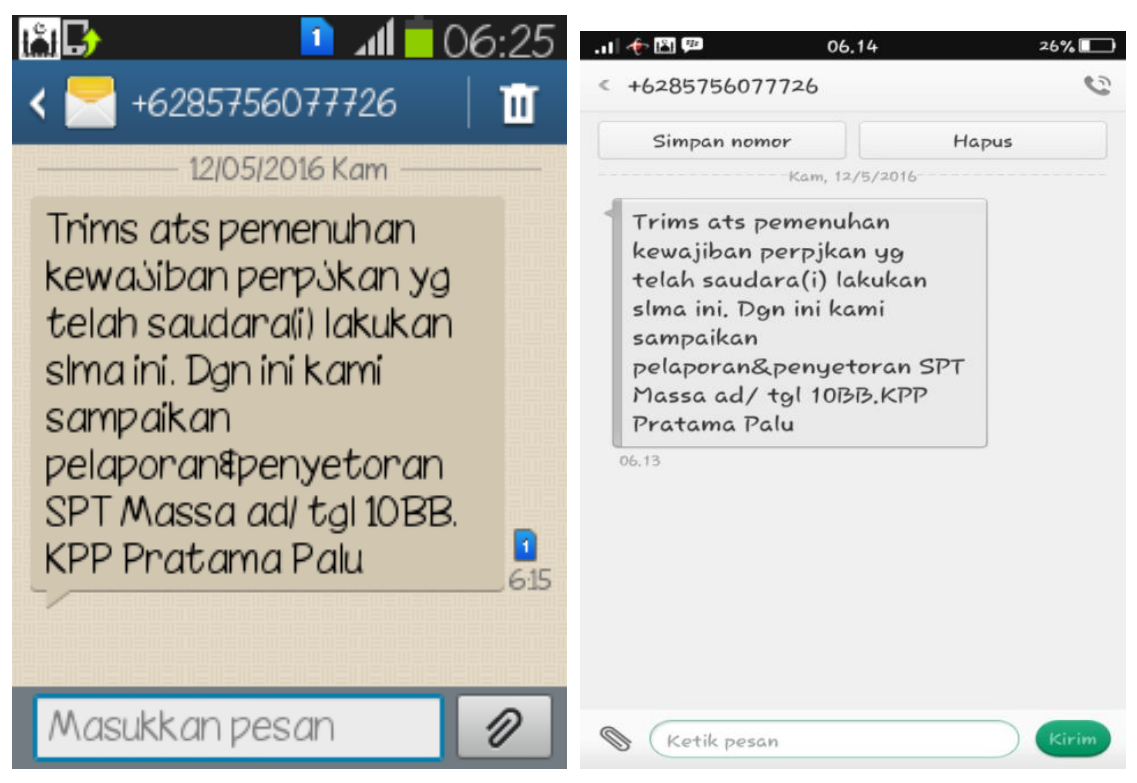

Gambar 5 Screenshots pesan yang dikirim

b) Pengiriman nomor handphone yang belum terdaftar.

Pengiriman nomor handphone yang belum terdaftar digunakan untuk mengirim kembali sms yang berstatus error . 


\section{KESIMPULAN}

Dari hasil penelitian, penggunaan aplikasi sms gateway pengirim informasi pelaporan dan penyetoran SPT Masa diharapkan dapat menghasilkan informasi yang cepat dan tepat bagi wajib pajak sehingga penunggakan pajak dapat diminimalisir. Dengan menggunakan aplikasi sms gateway dapat diperoleh keuntungan antara lain sebagai berikut:

1. Aplikasi sms gateway dirancang sebagai alternatif bagi pihak KPP Pratama untuk mengingatkan wajib pajak agar membayar pajak tepat waktu.

2. Aplikasi ini dapat menampung puluhan ribu no handphone wajib pajak dan menyimpan sms yang terkirim dalam kurun waktu lama.

3. Aplikasi ini dapat mengetahui status pesan yang dikirim gagal atau terkirim dan dapat mengirimkan kembali pesan yang gagal pada menu kirim pesan.

4. Aplikasi ini memberikan biaya yang minimum.

\section{DAFTAR PUTAKA}

[1] Habibi. 2015. Perancangan aplikasi Sms Gateway untuk meningkatkan kualitas pelayanan informasi pemadaman listrik di PT PLN (Persero) Kota Palu, Fakultas MIPA Universitas Tadulako, Palu.

[2] Laili.A. 2013. Membangun Kepatuhan Menuju Masyarakat Sadar Pajak. (Online). http://www.pajak.go.id/content/article/membangun-kepatuhan-menuju-masyarakat-sadarpajak, diakses 11 Januari 2016.

[3] R.Muchlisin. 2012. Pengertian dan Sejarah SMS. (Online). Teori SMS (Short Message Service)_ KajianPustaka.com.htm/ diakses pada tanggal 20 November 2015.

[4] P.Sandri. 2010. Peranan Kantor Wilayah Direktorat Jenderal Pajak Jawa Tengah II Dalam $\begin{array}{llll}\text { Meningkatkan Kinerja Satuan Kerja (Online). } & \end{array}$ http://core.ac.uk/download/pdf/12348873.pdf/, diakses pada tanggal 18 November 2015.

[5] www.pajak.go.id 